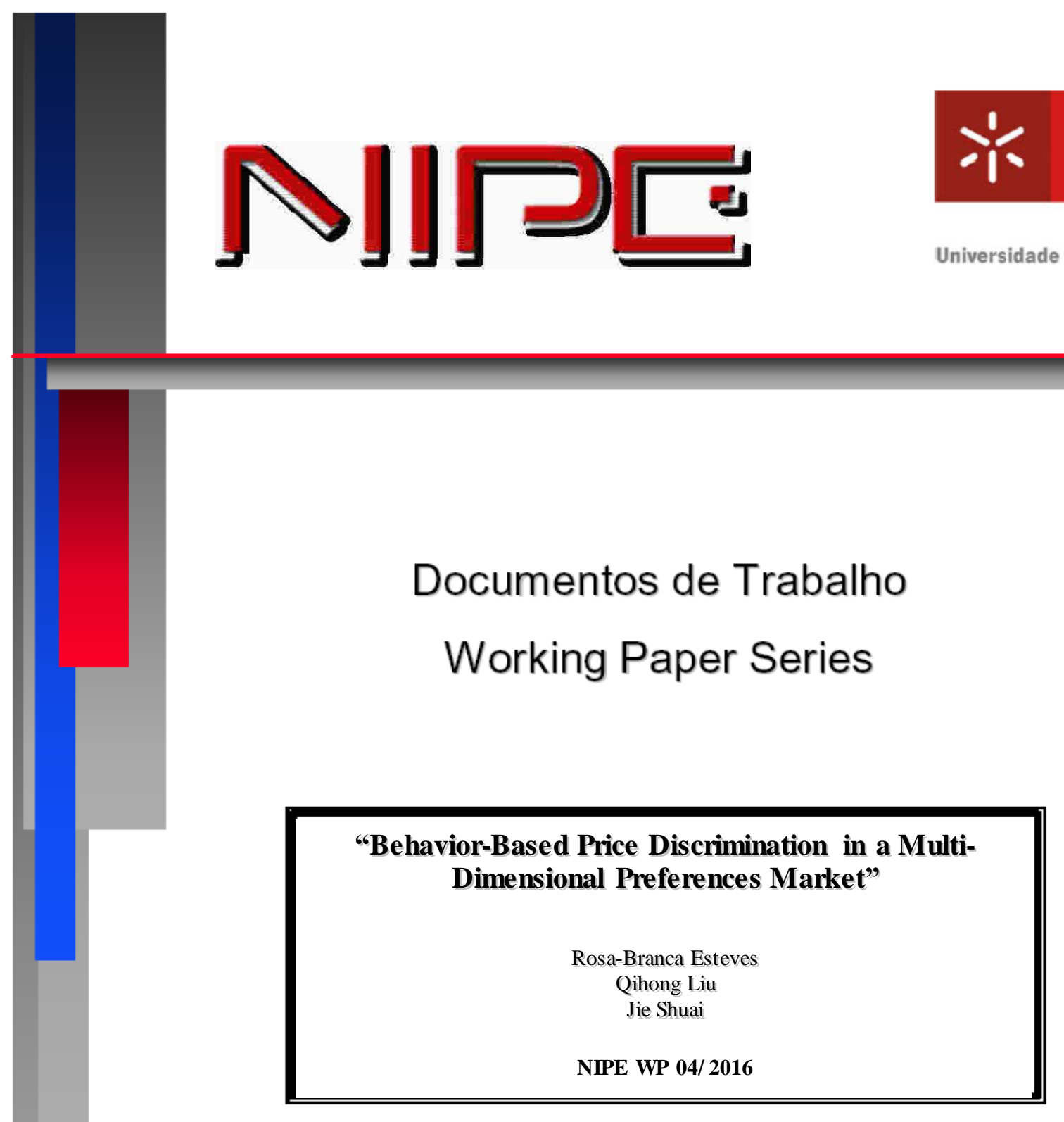

NÚCLEO DE INVESTIGAÇÃO EM POLÍTICAS ECONÓMICAS UNIVERSIDADE DO MINHO 


\section{"Behavior-Based Price Discrimination in a Multi-Dimensional Preferences Market"}

Rosa-Branca Esteves

Qihong Liu

Jie Shuai

\section{NIPE* WP 04/2016}

URL:

http://www.nipe.eeg.uminho.pt/

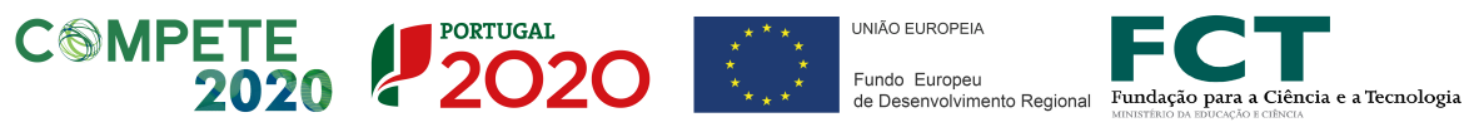




\title{
Behavior-Based Price Discrimination in a Multi-Dimensional Preferences Market
}

\author{
Rosa-Branca Esteves* $\quad$ Qihong $\mathrm{Liu}^{\dagger} \quad$ Jie Shuai ${ }^{\ddagger}$
}

March 9, 2016

\begin{abstract}
This article is a first look at the profit and welfare effects of behavior-based price discrimination in a two-period multi-dimensional preferences model. Compared to one-dimensional models, we show that firms compete less aggressively in both periods and so new results are obtained. Specifically, under forward looking consumers and two symmetric dimensions, BBPD boosts industry profits at the expense of consumers. However, we show that the standard onedimensional welfare results can prevail under asymmetric dimensions and myopic consumers.
\end{abstract}

Keywords: Multi-dimension; competitive price discrimination; customer recognition.

JEL Classification Codes: D43, L13, L40

\section{Introduction}

In many markets with repeat purchases firms usually face customers with multi-dimensional preferences (e.g. for product taste, brands, store's location, and so on). When price discrimination is permitted and trade among consumers is not feasible, it is common for a firm to offer different prices to its repeat customers and to those who bought from a rival before. This form of price discrimination, termed Behavior-Based Price Discrimination (henceforth BBPD), sometimes also

*Department of Economics and NIPE, University of Minho, Campus de Gualtar, 4710 Braga, Portugal. Email:rbranca@eeg.uminho.pt . Phone:+351253601932 .

${ }^{\dagger}$ Department of Economics, University of Oklahoma, 308 Cate Center Drive, Norman, OK 73019. E-mail: qliu@ou.edu. Phone: (405) 325-5846.

${ }^{\ddagger}$ Wenlan School of Business, Zhongnan University of Economics and Law, 182 Nanhu Ave., East Lake High-tech Development Zone, Wuhan 430073, P.R.China. Email: shuaijie@gmail.com. 
called price discrimination based on purchase history or dynamic pricing, is widely observed in many markets. In the communications markets, for instance, firms frequently offer a lower price to a customer who has been using a competitor's service. Similar pricing strategies are employed in markets such as supermarkets, web retailers, credit cards, banking services and electricity and gas. ${ }^{1}$ Although this type of competitive price discrimination has received wide attention in the economics literature in recent years ${ }^{2}$ the literature has hitherto focused on the assumption that consumer preferences are one-dimensional. Interestingly, in some markets where firms often discriminate between their own and the rivals' consumers, consumer preferences might be better represented by a multi-dimensional framework.

To motivate our model suppose that consumer preferences for two companies, say McDonald's (Mc) and Burger King (BK) are modeled taking into account two dimensions: the brand preference dimension and the store's physical location dimension. This suggests that a specific consumer might have a strong preference for Mc in the brand dimension while he might have a strong preference for BK in the physical location dimension. Considering our motivating example, suppose that Mc and BK are running a mobile price advertising campaign. Both are able to distinguish a repeated customer from a new one and they have access to tools that allow them to send mobile ads with different offers (prices) to old and new customers. Companies have, however, no information about individuals' true brand preference/location. A potential customer who is recognized as a repeated customer by BK can receive a targeted offer by BK. That same consumer may also be tracked by Mc which will recognize him/her as a new one and send a special offer. If the last offer is compelling enough, Mc can entice the consumer to travel to its store. While in the standard one-dimensional analysis a consumer who bough from BK in period 1 is necessarily closer to BK in that dimension, in a two-dimensional setting a consumer who bough from BK in period 1 might be closer to BK in one dimension but closer to $\mathrm{Mc}$ in the other one. Therefore, in this new setting some important issues are the following. What changes in terms of the companies' pricing strategies when we move from a one to a multi-dimensional framework? Do firms compete more or less aggressively in prices? In what circumstances is BBPD a profitable strategy for companies? Do consumers benefit from BBPD?

Our base model follows Fudenberg and Tirole (2000) by considering a two-period duopoly with a multi-dimensional horizontal product differentiation, where firms cannot commit to future prices, and can quote a different price to old/new customers. This paper offers important insights to the

\footnotetext{
${ }^{1}$ A recent report by the Office of Gas and Electricity Markets (Ofgem (2008)), the regulator for Britain's gas and electricity industries, has revealed that, in this industry: $(i)$ a substantial fraction of consumers are 'switchers' in the sense that they constantly seek out for the best deal in the market; and (ii) suppliers are well aware of these consumers' dynamics and do take them into account in their pricing decisions. In particular, "companies charge more to existing ("sticky") customers whilst maintaining competitiveness in more price sensitive segments of the market. Available for download at: http://www.ofgem.gov.uk/Markets/RetMkts/ensuppro/Pages/Energysupplyprobe.aspx

${ }^{2}$ Chen (2005), Fudenberg and Villas-Boas (2006) and Esteves (2009) present updated literature surveys on BBPD.
} 
understanding of the firms' pricing decisions to their strong and weak market segments in markets with multi-dimensional preferences. An important contribution is to show that competitive price discrimination based on purchase history needs not necessarily lead to the prisoners' dilemma result that generally follows in one-dimensional markets that exhibit best-response asymmetry. In fact, our analysis reveals that the practice of BBPD in a symmetric two-dimensional model hurts second period profit but boosts first period profit as well as overall profits. Further, in contrast to the general presumption in one-dimensional models that BBPD is not bad for consumers, we show that in a symmetric two-dimensional setting do in fact BBPD raise industry profits at the expense of consumers. Further, another important contribution is to clearly describe what market features are needed for BBPD to boost industry profits at the expense of consumers. The extension of the model to 2 asymmetric dimensions reveals that sufficient symmetry is a key determinant for our results.

Literature review This paper is mainly related to two strands of the literature, namely the literature on competition in multi-dimensional product differentiation markets and the literature on competitive price discrimination, mainly the literature on behavior-based price discrimination.

In a seminal paper, Irmen and Thisse (1998) analyze duopoly location choice in a general $n$-dimensional model. With the assumption of strong dominance, they show that firms want to maximize differentiation on the dominant dimension but minimize differentiation on all other dimensions. Liu and Shuai (2013) employs a similar model of 2-group price discrimination. Their model is one-period, and firms price discriminate based on exogenous information about consumers. In contrast, we consider a two-period model here where consumer information is generated endogenously through first-period consumer choices. Nevertheless, our results are similar in spirit in the sense that price discrimination (whether based on exogenous or endogenous information) can benefit firms at the cost of consumers, once we allow product differentiation to occur on more than one dimension.

This paper has also important connections with the literature on BBPD in one-dimensional competitive markets. Two approaches have been considered so far. In the switching costs approach, consumers initially view the two firms as perfect substitutes; but in the second period they face a switching cost if they change supplier. In this setting, purchase history discloses information about exogenous switching costs (e.g. Chen, 1997 and Taylor, 2003). Differently, in the brand preferences approach with fixed preferences across periods (e.g. Villas-Boas, 1999; Fudenberg and Tirole, 2000; Esteves, 2010), purchase history discloses information about a consumer's exogenous brand preference for a firm. Although the framework of competition differs in both approaches their predictions have some common features. In these models the market exhibits best-response asymmetry (Corts, 1998): the strong market segment of one firm is the weak market segment of the competitor. A common finding in such models is that firms charge lower prices to customers in weak market segments (new/rival's customers) than to customers in strong segments (old customers) 
and, in comparison to uniform pricing, equilibrium profits fall with price discrimination - firms find themselves in the classic prisoner's dilemma. ${ }^{3}$ Nonetheless, important differences arise in both approaches when taking into account the effects of poaching on initial prices. While in the brand preference approach initial prices are high and then decrease (e.g. Fudenberg and Tirole, 2000), in the switching costs approach the reverse happens (e.g. Chen, 1997).

This article contributes to the literature on price discrimination based on purchase history by investigating the profit and welfare effects of BBPD in a two-dimensional consumer preferences model. By doing so, we show that BBPD can boost industry profits at the expense of consumers. Chen and Pearcy (2010) have also shown that profits can increase with BBPD in a one dimensional consumer preferences model. However, this is only the case when consumer preferences are weakly correlated across time. Although our framework is different from Chen and Pearcy (2010) (preferences are two-dimensional and fixed across periods), both papers seem to highlight that the practice of BBPD in the context of a certain level of uncertainty about consumer preferences softens price competition and allows firms to use BBPD as a profitable pricing strategy.

The rest of the paper is organized as follows. We present the model in Section 2. Section 3 analyzes the 2-dimensional base model with symmetric dimensions. Then Section 4 discusses the welfare effects of BBPD and Section 5 discusses the robustness of our results to few extensions. We conclude in Section 6. Proofs of Lemmas and Propositions are relegated to the Appendix.

\section{The model}

Two firms A and B produce at zero marginal cost nondurable goods A and B. ${ }^{4}$ There are two periods, 1 and 2. The total number of consumers in the market is normalized to one. In each period, each consumer wishes to buy a single unit of the good from either firm A or B, and he/she is willing to pay at most $V$. The reservation value $V$ is sufficiently large so all consumers buy in the equilibrium (covered market). Consumers have exogenous preferences for goods that are present from the start and remain fixed over the two periods of consumption. ${ }^{5}$ Specifically, consumer preferences are specified in a 2-dimensional Hotelling model or on the unit square $[0,1]^{2}$, with firm $A$ located at $(0,0)$ and firm $B$ located at $(1,1)$. Consumers are uniformly distributed on the two dimensions and distribution on the two dimensions is independent from each other. The location of a consumer on the square, i.e. $(x, y) \in[0,1]^{2}$, represents his/her two-dimensional preference for

\footnotetext{
${ }^{3}$ More recently, also in a one-dimensional approach, Chen and Pearcy (2010) and Shin and Sudhir (2010) have shown that profits can increase with price discrimination, basically when consumer preferences are weakly correlated across time as well as in the case of high enough consumer heterogeneity.

${ }^{4}$ The assumption of zero marginal costs can be relaxed without altering the basic nature of the results derived throughout the model.

${ }^{5}$ For a one-dimensional model of BBPD with imperfect correlated preferences across periods see Chen and Pearcy (2010).
} 
goods (e.g. preferences for brand name/good; characteristic 1/characteristic 2 of the good; store location/good). Further, consumers incur a disutility from travelling to the location of each firm (good), which is quadratic in the distance traveled. ${ }^{6}$ For a consumer located at $(x, y)$ buying one unit of the good from $\mathrm{A}$ at price $p_{A}$, the indirect utility is written as

$$
u_{A}=V-p_{A}-t x^{2}-t y^{2}
$$

where $t$ is the unit transport cost on either dimension. ${ }^{7}$ Similarly, if the consumer buys from firm $B$ at price $p_{B}$ his/her indirect utility is written as

$$
u_{B}=V-p_{B}-t(1-x)^{2}-t(1-y)^{2} .
$$

Thus, our assumptions are quite standard in the literature except that we consider a twodimensional rather than the common one-dimensional model.

Suppose firms cannot commit to future prices. Consumers reveal information about their preferences by their first-period choice. Thus, in period 1 each firm sets a uniform price because it has no information to price discriminate. Observing the prices, consumers make first-period purchasing decisions. Depending on the purchasing decisions in period 1, the whole market is divided into two markets: firm A's turf (Market 1) and firm B's turf (Market 2). Hence, in period 2, each firm can distinguish consumers in the two markets and price discriminate accordingly: each firm will choose a price to its own past customers and another one to those consumers who purchased from the rival before. In each period, firms choose their prices simultaneously. A strategy for firm $i$, $i=A, B$, specifies $p_{1 i}$ in period 1 and prices $\left(p_{2 i 1}, p_{2 i 2}\right)$ in period 2 based on consumers' previous purchases, where $p_{2 i 1}$ and $p_{2 i 2}$ are, respectively, firm $i$ 's prices for consumers in market 1 (those who bought from firm A in period 1) and for consumers in market 2 (those who bought from firm B in period 1). We look for a subgame perfect Nash equilibrium. Before proceeding, we first explain how consumers would make their purchasing decisions for any given prices.

\section{The Marginal Consumers Line (MCL)}

In particular, we derive the set of consumers who are indifferent between buying from either firm. We show that they form a line and we call it the Marginal Consumers Line (MCL). Then consumers to the left (or bottom) of the MCL will purchase from firm $A$ while consumers to the right (or above) of the MCL will purchase from firm $B$.

Look first at second-period price competition. Let $p_{2 i j}, i=A, B$ with $j=1,2$ denote second period prices offered by firms $\mathrm{A}$ and $\mathrm{B}$ to consumers in market $j$. A consumer is indifferent between the two firms if and only if $u_{2 A}(x, y)=u_{2 B}(x, y)$, from which we obtain

$$
V-p_{2 A j}-t x^{2}-t y^{2}=V-p_{2 B j}-t(1-x)^{2}-t(1-y)^{2}
$$

\footnotetext{
${ }^{6}$ In our setup, linear and quadratic transport cost lead to the same equilibrium prices and profits.

${ }^{7}$ We consider the case of asymmetric dimensions $\left(t_{1} \neq t_{2}\right)$ in the Extensions.
} 
which yields

$$
x=1-y+\frac{p_{2 B j}-p_{2 A j}}{2} .
$$

Look next at first-period competition. Let firm A's first-period price be $p_{1 A}$ and firm B's first-period price be $p_{1 B}$. The marginal consumer in the first period will surely switch in the second period to take advantage of the poaching price. Given the first-period prices, the indifferent consumer between buying from firm $\mathrm{A}$ in period 1 at price $p_{A 1}$ and then buying from $\mathrm{B}$ in period 2 at the poaching price $p_{2 B 1}$, or buying from $\mathrm{B}$ in period 1 at price $p_{1 B}$ and then buying from $\mathrm{A}$ at the poaching price $p_{2 A 2}$ is located at the marginal consumers line MCL, characterized by $u_{1 A}+\delta u_{2 B}=u_{1 B}+\delta u_{2 A}$, or, equivalently

$p_{1 A}+t x^{2}+t y^{2}+\delta\left[p_{2 B 1}+t(1-x)^{2}+t(1-y)^{2}\right]=p_{1 B}+t(1-x)^{2}+t(1-y)^{2}+\delta\left[p_{2 A 2}+t x^{2}+t y^{2}\right]$.

which yields

$$
x=1-y+\frac{p_{1 B}-p_{1 A}+\delta\left(p_{2 A 2}-p_{2 B 1}\right)}{2 t(1-\delta)}
$$

\subsection{Uniform pricing in a two-dimensional model}

The case where firms cannot price discriminate, meaning that each firm sets a uniform price to all consumers in each period, is used as a benchmark in the subsequent analysis. Suppose that for some reason (e.g. regulation, costs of changing prices, technological restrictions) firms in the second period can not price discriminate. In that case, the two-period model reduces to two replications of the static equilibrium which has been analyzed in several existing studies (e.g. Liu and Shuai, 2013; Tabuchi, 1994). Based on these models it is straightforward to prove that firm $i$ 's equilibrium prices and profits (marked with superscript $u$, for uniform pricing) in each period are:

$$
\begin{gathered}
p_{1 i}^{u}=p_{2 i}^{u}=t, \\
\pi_{1 i}^{u}=\pi_{2 i}^{u}=\frac{t}{2},
\end{gathered}
$$

and firm $i$ 's overall profit is equal to

$$
\pi_{i}^{u}=\frac{t}{2}(1+\delta)
$$

\section{Equilibrium Analysis}

As usual in order to find the Subgame Perfect Nash Equilibrium we solve the game working backwards from the second period. 


\subsection{Second-period}

In period 2, each firm is able to distinguish its own customers from those who bought from the rival before, and charge different prices accordingly. Without loss of generality, assume that given the firms' first-period prices, the first-period MCL crosses the bottom horizontal line at $\left(x_{1}, 0\right)$ with $x_{1} \in(0,1] .{ }^{8}$ The MCL thus splits the square into two markets: market 1 consists of those customers who bought from firm $A$ in period 1, while market 2 is made off consumers who bought from firm $\mathrm{B}$ in period 1. In the second period firms compete in these two markets separately. We first establish the equilibrium demand structure in period 2, given the prices tailored to each market.

Lemma 1 In period 2, MCL must cross the bottom horizontal line in market 1 and cross the top horizontal line in market 2.

Proof. Let us start with market 1 which is itself a triangle. MCL cannot possibly cross top horizontal line in period 2 .

What about market 2? Suppose that MCL crosses bottom horizontal line at $\left(x_{3}, 0\right)$, with $x_{3} \in\left(x_{1}, 1\right]$. Under this demand structure, we solve the equilibrium prices. We find that they lead to $x_{3}>1$, suggesting that MCL crosses the top horizontal line, violation.

Based on Lemma 1, we draw the demand structure as in Figure 1. Suppose that $\mathrm{MCL}_{21}$ crosses the bottom horizontal line in market 1 at $\left(x_{2}, 0\right)$, and the $\mathrm{MCL}_{22}$ crosses the top horizontal line at $\left(x_{3}, 1\right)$ in market 2 (firm $B$ 's old customers).

Let $q_{2 i j}$ (determined in the Appendix) represent firm $i=A, B$ 's second-period demand in market $j=1,2$, then firm $i$ 's second-period profit in market $j$ equals:

$$
\pi_{2 i j}=p_{2 i j} \cdot q_{2 i j}
$$

In the second period, each firm chooses the second-period prices in order to maximize expression (4). Overall second-period profit for firm $i$ is $\pi_{2 i}=\pi_{2 i 1}+\pi_{2 i 2}$.

\footnotetext{
${ }^{8}$ Due to firm symmetry, if MCL crosses the top horizontal line, then one can switch firm $A$ and $B$ 's location and labeling.
} 


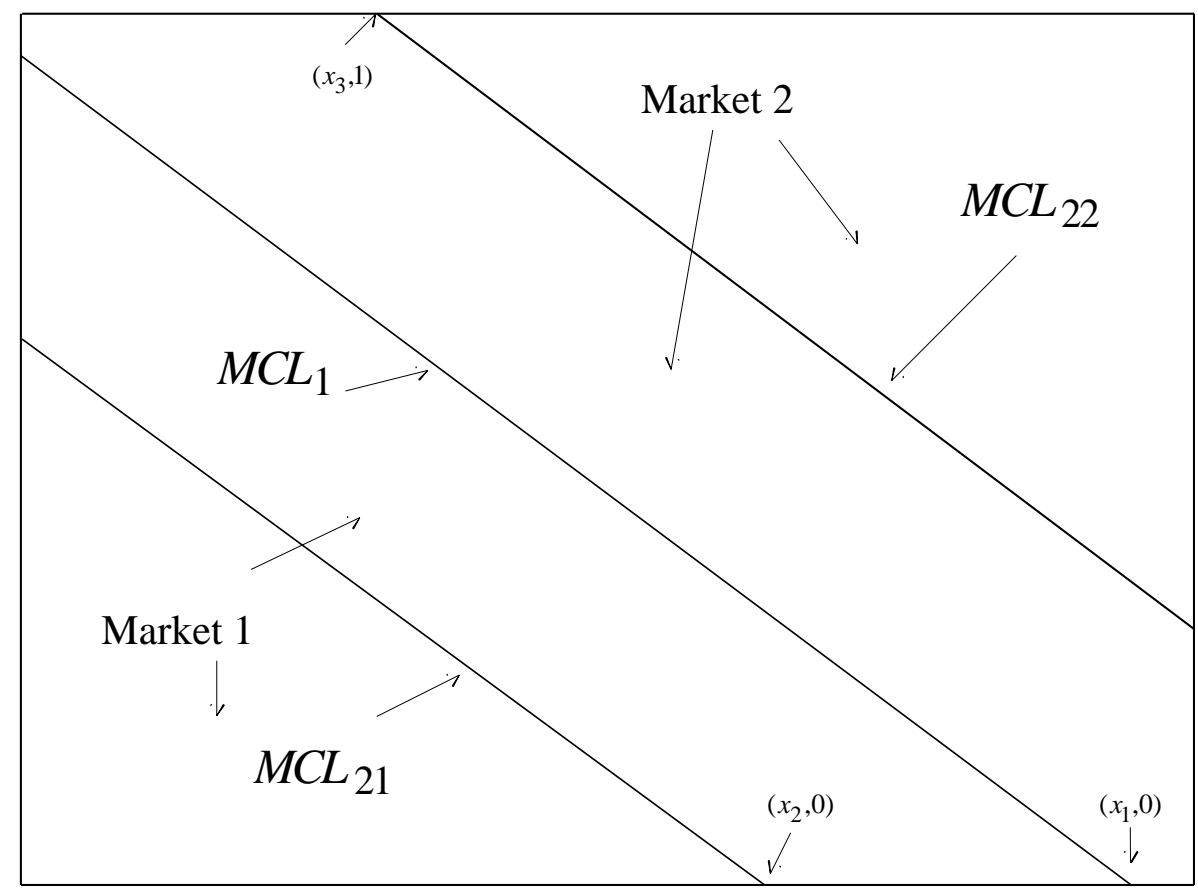

Figure 1: Demand structures (MCLs) in period 1 and 2.

The next Lemma characterizes the second-period price equilibrium.

Lemma 2 Suppose that the $M C L$ crosses the bottom horizontal line at $\left(x_{1}, 0\right)$ in period 1 . Then second period equilibrium prices are:

(i) if $x_{1} \leq \frac{2}{3}$ :

$$
\begin{gathered}
p_{2 A 1}=2 t\left(1-x_{1}\right), \quad p_{2 B 1}=0 \\
p_{2 A 2}=\frac{t}{4}\left(3 \sqrt{9-4 x_{1}^{2}}-5\right), \quad p_{2 B 2}=\frac{t}{4}\left(\sqrt{9-4 x_{1}^{2}}+1\right),
\end{gathered}
$$

(ii) if $\frac{2}{3} \leq x_{1} \leq 1$ :

$$
\begin{aligned}
& p_{2 A 1}=\frac{t}{4}\left(\sqrt{4 x_{1}^{2}+1}+1\right), \quad p_{2 B 1}=\frac{t}{4}\left(3 \sqrt{4 x_{1}^{2}+1}-5\right), \\
& p_{2 A 2}=\frac{t}{4}\left(3 \sqrt{9-4 x_{1}^{2}}-5\right), \quad p_{2 B 2}=\frac{t}{4}\left(\sqrt{9-4 x_{1}^{2}}+1\right) .
\end{aligned}
$$


Proof. See the Appendix.

When $\frac{2}{3} \leq x_{1} \leq 1$, firm $\mathrm{A}$ and B's second-period profits are respectively equal to:

$$
\pi_{2 A}=\frac{t}{32}\left[-40+\sqrt{1+4 x_{1}^{2}}+24 x_{1}^{2}+\sqrt{1+4 x_{1}^{2}} x_{1}^{2}+19 \sqrt{9-4 x_{1}^{2}}-9 x_{1}^{2} \sqrt{9-4 x_{1}^{2}}\right]
$$

and

$$
\pi_{2 B}=\frac{t}{32}\left[-24 x_{1}^{2}+9 \sqrt{1+4 x_{1}^{2}} x_{1}^{2}+8+\sqrt{1+4 x_{1}^{2}}+3 \sqrt{9-4 x_{1}^{2}}-x_{1}^{2} \sqrt{9-4 x_{1}^{2}}\right] .
$$

When $x_{1} \leq \frac{2}{3}$, then:

$$
\pi_{2 A}=\frac{t}{32}\left[53 x_{1}^{2}-32 x_{1}^{3}-41+19 \sqrt{9-4 x_{1}^{2}}-9 x_{1}^{2} \sqrt{9-4 x_{1}^{2}}\right],
$$

and

$$
\pi_{2 B}=\frac{t}{118}\left(1+\sqrt{9-4 x_{1}^{2}}\right)^{3}
$$

Figures 2 and 3 plot both firms' prices targeted to market 1 and 2 as a function of $x_{1}$, for the case where $t=1$ :

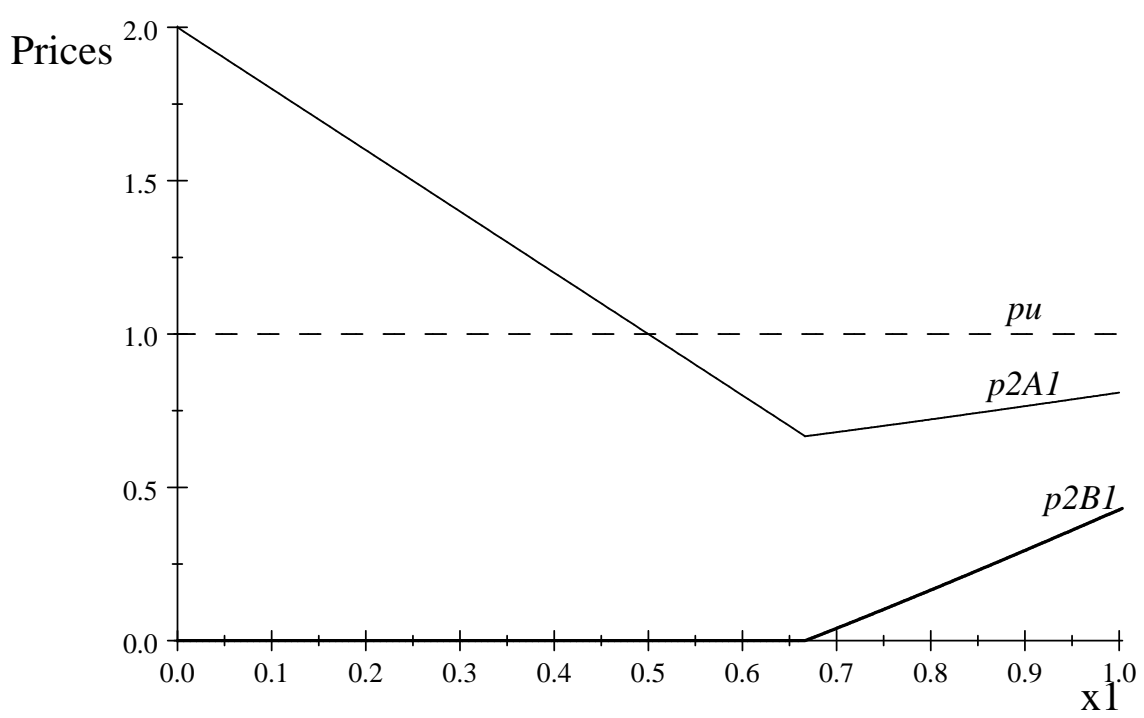

Figure 2: Firm A and B's second-period prices for market 1 


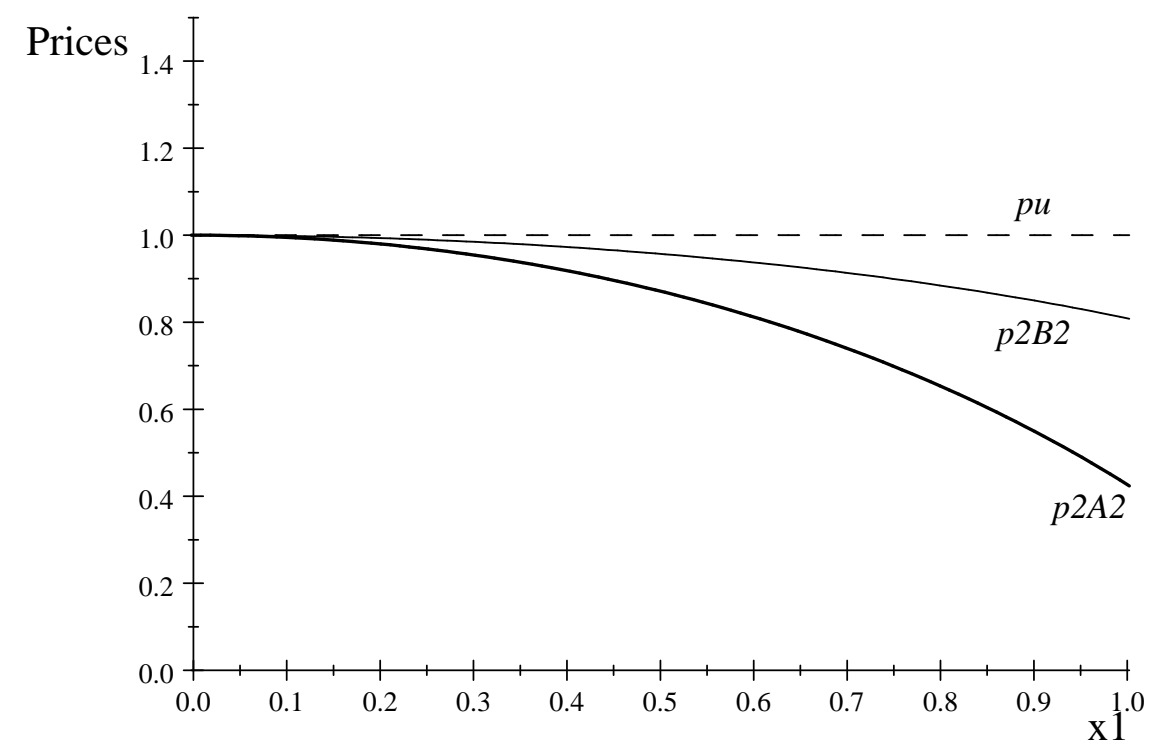

Figure 3: Firm A and B's second-period prices for market 2

Corollary 1. Regarding the prices targeted to market 1 and 2, moving from uniform pricing to $B B P D$ :

(i) increases the price for firm A's old consumers, i.e., $p_{2 A 1}>p^{u}$ as long as $x_{1}<\frac{1}{2}$, otherwise the reverse happens, thus $p_{2 A 1} \leq p^{u}$.

(ii) decreases the price for firm B's new consumers, regardless of $x_{1}$.

(iii) decreases both firms' prices targeted to market 2, regardless the value of $x_{1}$.

Look first at prices targeted to market 2. The previous corollary suggests that compared to uniform pricing, as long as $x_{1}$ is not null, both firms charge a lower price to customers in market 2 . Specifically, we observe that $p_{2 A 2}<p_{2 B 2}<p^{u}$. As $x_{1}$ increases the same happens to the difference between $p_{2 B 2}$ and $p_{2 A 2}$. This suggests that firm $\mathrm{A}$ is more likely to poach some of firm B's previous customers the higher is $x_{1}$.

Look next at prices targeted to market 1 . Corollary 1 suggests that the price offered by firm B to new customers is always below the uniform price, while the price offered by firm A to its old customers can be above/below its uniform counterpart. Note that the lower is $x_{1}$ the higher is firm B's market share in period 1 (and so the size of market 2). Indeed, when $x_{1}$ is small enough, attracting new consumers is not profitable for firm B as it would require a below-marginal-cost price. This case is presented in point (i) of Lemma 2 where firm B prefers the dominant strategy of setting a poached price equal to the marginal cost (i.e., $p_{2 B 1}=0$ ) in firm A's turf (market 1). From the point of view of firm A, the lower is $x_{1}$ the weaker the price competition in its own turf, 
as the rival becomes less aggressive. For this reason, when $x_{1}<\frac{2}{3}$, the equilibrium price offered by firm $\mathrm{A}$ to its old customers is decreasing in $x_{1}$, and can be above the uniform price. This finding is in contrast to what happens in the one-dimensional model, where the second period prices are all below the uniform price when BBPD is permitted. Taking into account the equilibrium prices targeted to market 1 , we also find that if $x_{1}$ is not sufficiently high then firm B (the dominating firm in period 1) does not attract any consumer in market 1 , even though it charges a price equal to the marginal cost. In contrast, when $x_{1}$ is sufficiently high (the first-period market share is balanced enough), and in this case firm B is able to attract some consumers in market 1 . Consequently, both firms' prices targeted to market 1 are below the uniform price. Finally, it is important to stress that in the case where $x_{1}=1$, then both firms share equally the market in period 1 . In this case, as usual in the literature, we observe that $p_{2 B 1}<p_{2 A 1}<p^{u}$, and firm B is able to poach some of firm A's previous customers. Furthermore, when $x_{1}=1$, we have that $p_{2 A 1}=p_{2 B 2}$ and $p_{2 A 2}=p_{2 B 1}$.

\section{$3.2 \quad$ First-period}

We now move on to period 1 . We first show that there is no asymmetric subgame perfect Nash equilibrium (i.e., with $p_{1 A} \neq p_{1 B}$ ).

Lemma 3 There is no asymmetric subgame perfect nash equilibrium (with $p_{1 A} \neq p_{1 B}$ ).

Proof. See the Appendix.

Having ruled out asymmetric equilibrium, we look for the symmetric SPNE and we find a unique one, characterized in the next Proposition.

Proposition 1 When firms can engage in BBPD in a two-dimensional market, in the unique subgame perfect nash equilibrium:

(i) first-period prices are

$$
p_{1 A}=p_{1 B}=t\left(1+\frac{13 \sqrt{5}-25}{10} \delta\right)
$$

(ii) second-period 2 prices are

$$
\begin{gathered}
p_{2 A 1}=p_{2 B 2}=t\left(\frac{1+\sqrt{5}}{4}\right) \\
p_{2 A 2}=p_{2 B 1}=t\left(\frac{3 \sqrt{5}-5}{4}\right)
\end{gathered}
$$

(iii) second-period profits are

$$
\pi_{2 A}=\pi_{2 B}=t\left(\frac{3 \sqrt{5}-4}{8}\right) ; \text { and }
$$


(iv) each firm's overall discounted profit is

$$
\pi^{B B P D}=t\left(\frac{1}{2}+\frac{41 \sqrt{5}-70}{40} \delta\right) .
$$

Proof. See the Appendix.

\section{Competitive and welfare effects}

This section looks at the price, profit, consumer surplus and welfare effects of BBPD in a twodimensional consumer preferences market. In order to provide this analysis, prices, profits and consumer surplus resulting under BBPD in the two-dimensional model are compared with (i) the benchmark case of no BBPD, which serves to isolate the impact of price discrimination; and with (ii) BBPD in the one-dimensional model.

\subsection{Effect on prices}

Most of the existing academic literature on BBPD suggests that when the market exhibits best-response asymmetry-one firm's weak market is the other's strong market-the optimal choice for each firm is to offer a lower price to its low preference consumers than to its high preference consumers (e.g. Chen, 1997; Villas-Boas, 1999; Fudenberg and Tirole, 2000; Esteves, 2010). ${ }^{9}$ In what follows we investigate this issue and also how BBPD affects the firms' first-period decisions.

Compared to the uniform benchmark case, the equilibrium price with BBPD is higher for all consumers in period 1 but lower for all consumers in period 2, the same as in the one dimensional model (Fudenberg and Tirole, 2000). As purchase history reveals the consumers' brand preferences, each firm has an incentive to reduce the price to customers who bought from the rival before as an attempt to entice them to switch. However, because both firms set a lower price to customers in their weak markets, they induce the rival to be more aggressive in its strong market as well. Due to the intensified competition effect of price discrimination, all prices fall in period 2. Thus our analysis confirms the usual findings in the literature, suggesting that in the two-dimensional model firms also quote lower prices to their weak segment than to their strong segment of consumers.

However, it is important to stress that although second-period equilibrium prices fall with price discrimination in our set-up, the same as in Fudenberg and Tirole (2000), second-period prices in the two-dimensional model are above their one dimensional counterparts. According to Proposition 1,

repeated consumers pay $t\left(\frac{1+\sqrt{5}}{4}\right)$ which is above the price they pay in the one-dimensional approach

\footnotetext{
${ }^{9}$ An exception is Shin and Sudhir (2010) who show that firms can charge a low price to their strong customers when consumer preferences stochasticity across time and consumer heterogeneity are simultaneously high enough.
} 
(i.e., $\left.\frac{2 t}{3}\right)$. Similarly, in the two-dimensional model, the price for new customers is $t\left(\frac{3 \sqrt{5}-5}{4}\right)$ which is also above its counterpart of $\frac{1}{3} t$ in the one-dimensional set-up. This suggests that the existence of a second-dimension acts to soften price competition in period 2, allowing firms to raise second-period prices, compared to the one-dimensional model. The driving force behind this result is the following. In a one dimensional model all consumers in say firm B's weak market have a preference for firm A, suggesting that firm B wants to price aggressively in this market. In contrast, in a two-dimensional model, not all consumers in a firm's weak market have a preference for the rival's product in the two dimensions. Indeed, in a two-dimensional model, some consumers in, for instance, firm B's weak market might have a preference for firm A in one dimension while they might prefer firm B in the other dimension. This suggests that compared to the one-dimensional model, firm B has now fewer incentives to reduce the price to consumers who bought from firm A in period 1. Because prices are strategic complements, when firm B prices less aggressively in its weak market, firm A reacts in the same way regarding the price tailored to its strong segment of the market. As a result of that, old and new customers face higher prices in the two-dimensional model.

As to the effect of BBPD on the first-period price, we find that it is equal to $t\left(1+\frac{13 \sqrt{5}-25}{10} \delta\right)$ in the two-dimensional model, while it is equal to $t(1+\delta / 3)$ in the one-dimensional set-up. Therefore, it is straightforward to see that as long as $\delta>0$, each firm charges a higher first-period equilibrium price when consumer preferences are two-dimensional. This highlights that BBPD has a stronger positive effect on the first-period price in our set-up than in the one-dimensional counterpart.

Before proceeding we discuss with more detail the main differences and intuitions behind the impact of BBPD on first-period prices in the one and two dimensional models. Consider first the one-dimensional model (Fudenberg and Tirole, 2000). Here, the reason why the first period price is above the uniform one is entirely explained by the decreased elasticity of demand. The intuition is the following. When consumers are sophisticated they anticipate the lower second period price and thus they become less price sensitive in period 1. This softens price competition in period 1, allowing firms to raise the first period equilibrium price. In contrast, when consumers are myopic, BBPD has no effect on the first period price equilibrium. Thus, in Fudenberg and Tirole (2000), compared to uniform pricing, firms do not distort their first-period price equilibrium when consumers are naive.

Consider next our two-dimensional framework. Here the decreased elasticity of demand can also explain in part why the first-period price is above its non-discrimination counterpart. This is specially the case when consumers are forward-looking. The reason is that, in contrast to what happens in Fudenberg and Tirole (2000), here we still find that firms price above the non-discrimination price in period 1 even when consumers are assumed to be naive (see the discussion in Section 5.2). Therefore, our analysis suggests that in the two-dimensional model apart from the decreased elasticity of demand there should be another driving force behind the higher first-period prices. 
In general it can be said that when firms can engage in price discrimination based on purchase history there are two effects on first-period prices: a consumer-side effect and a firm-side effect. When consumers are forward-looking they correctly anticipate lower second period prices, become less price sensitive in period 1 and so there is a positive effect on first-period prices. When firms are forward looking, they also take into account that changes in the first-period price change the firstperiod cutoff and thus change the nature of the second-period competition. In the one dimensional model of BBPD a change in the first-period price has no effect on second-period profit because with a uniform distribution a firm's marginal gains in one second-period market are exactly offset by losses in the other $\left(\frac{\partial \pi_{2}}{\partial p_{1}}=0\right)$. Thus, in Fudenberg and Tirole (2000) the decrease in the price sensitivity of consumers in period 1 that occurs when we move from no discrimination to BBPD fully determines the result of first-period prices above the non-discrimination level.

In the two-dimensional model we find that, with the uniform distribution, a change in the firstperiod price does not cancel out in the neighborhood of $x_{1}=1$, specifically we find that $\frac{\partial \pi_{2 A}}{\partial p_{1 A}}>0$, suggesting that firm A's marginal gains in one second-period market (higher price $p_{2 A 2}$ targeted to market 2) are higher than losses in the other (lower price $p_{2 A 1}$ targeted market 1 ). Put differently, the reason why BBPD raises first period prices in the two dimensional model is because the MCL in the second period crosses one horizontal line and one vertical line. In this case the length of the MCL depends on prices. If say firm A is aggressive in the first period, its strong market is larger in the second period, in equilibrium, the length of the MCL is likely to be larger, and more marginal consumers means that firm B would have more incentive to charge a lower price. Thus aggressive pricing in the first period will induce its competitor not only be aggressive in the first period, but also in the second period. In contrast when firm A charges a higher first period price, its strong market is smaller in the second period, in equilibrium, the length of the MCL is likely to be smaller, and less marginal consumers means that firm B would have less incentive to charge a lower price. Thus an increase in the first period price will induce its competitor not only to play less aggressively in the first period, but also in the second period. Consequently, each firm's first period price with BBPD is thus higher than its uniform counterpart. This is also true when consumers are myopic $(\delta=0)$, suggesting that in our framework BBPD leads to higher first-period prices even when consumers are myopic.

Summing up, compared to the one-dimensional framework our analysis highlights that price discrimination leads firms to compete less aggressively in both periods, suggesting that different profit effects can arise in the bi-dimensional consumer preferences set-up.

\subsection{Effect on profits}

An important question for academics, managers and practitioners is whether price discrimination by purchase history is a profitable strategy for firms in comparison to uniform pricing. In most 
the economic environments that have been used in the literature, oligopoly price discrimination based on customers past behavior tends to lower industry profits. This is generally the case in oligopoly markets characterized by best-response asymmetry and one-dimensional consumer preferences which are stable across time (e.g. Chen, 1997; Fudenberg and Tirole, 2000; Esteves, 2010; to name few). Our aim in this section is to investigate whether this common finding in the literature remains when we allow consumer preferences to be bi-dimensional and stable across time.

Compared to the non-discrimination benchmark, we find that price discrimination raises the equilibrium profit in period 1 whereas it reduces the equilibrium profit in period 2 . The next corollary summarizes the profit effects of BBPD in our model.

Corollary 2. In a two-dimensional consumer preferences model, Behavior-Based Price Discrimination hurts second period profit but boosts first period profit and overall profits.

An important contribution of this paper is to show that price discrimination by purchase history is a profitable strategy for firms when consumer preferences are two-dimensional. Indeed, Corollary 2 highlights that the positive effect of price discrimination on first-period profit dominates the negative effect on second-period profit, thus the ability of firms to engage in price discrimination based on purchase history actually raises the overall discounted equilibrium profit in a two-dimensional model. Note that $\pi^{B B P D}>\pi^{U}$, so BBPD actually raises overall profits relative to the uniform pricing. Consequently, this finding is in sharp contrast to the overall profit effect of BBPD in one-dimensional models, in which firms find themselves in the classic prisoner's dilemma when they employ BBPD. Obviously, the economic intuition behind our result is based on the previous explanation about the effect of BBPD on first and second period prices.

Compared to BBPD in one-dimensional models, we can show that the positive impact of BBPD on first period profit is stronger in a two-dimensional than in a one-dimensional model, thus:

$$
\pi_{1 i}^{2-\text { dimension }}>\pi_{1 i}^{1-\text { dimension }}>\left(\pi^{U}=\frac{t}{2}\right), \quad i=A, B .
$$

Additionally, straightforward computations show also that moving from a one-dimensional analysis to a two-dimensional one, reduces the negative impact of BBPD on second period profits. This yields

$$
\left(\pi^{U}=\frac{t}{2}\right)>\pi_{2 i}^{2-\text { dimension }}>\pi_{2 i}^{1-\text { dimension }}, \quad i=A, B
$$

Summing up, this paper contributes to the ongoing debate on the profit implications of this form of dynamic price discrimination, only made possible in the context of digital markets. Like Chen and Pearcy (2010) and Shin and Sudhir (2010) we find that BBPD can actually raise equilibrium profits. However, in their one-dimensional consumer preferences models this is only the case when the consumers' preference dependence across time is low. In fact, when preferences are fixed across time, industry profits fall under BBPD. 


\subsection{Effect on consumer surplus and overall welfare}

In this section we discuss the main policy implications for competition policy agencies and/or consumer advocates that can be derived from our theoretical model. Policy options against price discrimination by purchase history should be based on the whether price discrimination is likely to be beneficial to consumers or not. A general presumption in the literature on BBPD in onedimensional models with fixed preferences across time is that "price discrimination by purchase history ... is by and large unlikely to raise significant antitrust concerns. In fact, as the economics literature suggests, such pricing practices in oligopoly markets often intensify competition and potentially benefit consumers." (Chen, 2005, p. 123). Our goal in this section is to investigate what changes in terms of the consumer welfare effects when BBPD is employed in the context of a bi-dimensional model.

Interestingly, Corollary 3 shows that price discrimination based on consumers' past behavior will increase industry profits at the expense of consumers' surplus and overall welfare. It is important to stress that consumers in the middle, close to the main diagonal will be better off under BBPD. Those far away will be worse off. However, in aggregate terms they enjoy a lower surplus with BBPD than under uniform pricing. Therefore, our analysis highlights that the welfare effects of $\mathrm{BBPD}$ in a one dimensional setting-higher consumer surplus at the expense of industry profits and welfare-do not prevail when we allow preferences to be two-dimensional.

Corollary 3. In a two-dimensional model, compared to uniform pricing, Behavior-Based Price Discrimination harms consumer surplus and overall welfare.

The proof of Corollary 3 is straightforward. Regarding overall welfare note that total transport cost is minimized under uniform pricing. Therefore, social surplus must be lower under BBPD. Combined with higher profits under BBPD, it follows that in aggregate consumer surplus must be lower under BBPD than under uniform pricing.

In order to summarize the main literature findings and inform competition policy agencies, Table 1 shows the comparative static results obtained in a model of one-dimensional fixed preferences across time (Fudenberg and Tirole, 2000); in a model of one-dimensional correlated preferences across time (Chen and Pearcy, 2010) and in a model of two-dimensional fixed preferences across time. 
Table 1: Comparative static results

\begin{tabular}{cccc}
\hline Models & Overall Profits & CS & W \\
\hline \hline $\begin{array}{c}\text { OD model with fixed preferences } \\
\text { Fudenberg and Tirole (2000) }\end{array}$ & Below U & Above U & Below U \\
\hline $\begin{array}{c}\text { OD model with correlated preferences } \\
\text { Chen and Pearcy (2010) }\end{array}$ & $\begin{array}{c}\text { Below U (HD)/ } \\
\text { Above U (LD) }\end{array}$ & $\begin{array}{c}\text { Below U (LD)/ } \\
\text { Above U (HD) }\end{array}$ & Below U \\
\hline $\begin{array}{c}\text { TD model with fixed preferences } \\
\text { Present paper }\end{array}$ & Above U & Below U & Below U \\
\hline
\end{tabular}

(OD: one dimensional, TD: two-dimensional; LD: low dependence; HD: high dependence; U: uniform pricing)

Regarding the aggregate effects of $\mathrm{BBPD}$ on welfare, because there is no role for price discrimination to increase aggregate output, variations in welfare are uniquely explained by the "disutility" supported by those consumers who buy inefficiently. ${ }^{10}$ As a result of that, in comparison to no discrimination, BBPD hurts overall welfare in the three models considered. Table 1 also shows that in fact the profit and consumer welfare effects obtained in a one-dimensional model with fixed preferences are the reverse of their counterparts in the two-dimensional model of consumer preferences. Different conclusions are obtained when we compare our results with those obtained by Chen and Pearcy (2010). As expected they confirm the welfare effects in Fudenberg and Tirole (2000) when consumer preferences' dependence across the two periods is high. In contrast, when consumer preferences' dependence is low (or independent), like in our setting, they find that BBPD boosts industry profits at the expense of consumer welfare. In spite of the different assumptions considered in their model and in ours, the intuition behind the same profit and consumer welfare effect is based on what firms learn about consumer preferences. The existence of some level of uncertainty about consumer preferences-either due to the two-dimensional assumption or to unstable preferences across time-acts to soften price competition between firms which in turn enhances industry profits at the expense of consumers.

Summing up, taking into account our findings and those in the economics literature, we can say that conclusions regarding the profit and welfare effects of price discrimination based purchase history do depend on the way consumer preferences are modelled and on what is learned about consumers. Our results, thus, carry an important policy implications regarding the practice of price discrimination by purchase history. When the welfare standard adopted by competition authorities to appraise price discrimination based on purchase history is the consumers' welfare, ${ }^{11}$ our model

\footnotetext{
${ }^{10}$ For a model where BBPD can affect aggregate output see Esteves and Reggiani (2014).

${ }^{11}$ It should be noted, however, that the adoption of the consumers' welfare standard appears to be the current practice in the major antitrust jurisdictions. As Lyons (2002, p. 1) highlights, "most major competition authorities operate under legislation and guidelines that reject this [total surplus] standard, and no major competition authority seems to apply it consistently.
} 
suggests that they should scrutinize these pricing strategies with greater zeal in markets that could be reasonably well represented by the two-dimensional distribution assumption.

\section{Extensions}

In this section we discuss the main implications in terms of the profit and consumer welfare effects of $\mathrm{BBPD}^{12}$ when the base model is extended to (i) asymmetric dimensions and (ii) myopic consumers.

\subsection{Asymmetric dimensions $\left(t_{1} \neq t_{2}\right)$}

The previous analysis focused attention on a symmetric two-dimensional model where $t_{1}=t_{2}=$ $t$. So, it is natural to wonder what would be the implications for the proposed game if one allows for two asymmetric dimensions. Without loss of generality, assume that $t_{1} \geq t_{2}$. We only look for the symmetric equilibrium. Taking into account this possibility we find that when $t_{1} \geq t_{2}$, the slope of MCL is not necessarily -1 , but instead $-\frac{t_{1}}{t_{2}}$. The MCL line will cross both top and horizontal lines in period 1 . In period 2 , if $t_{2}$ is not too small relative to $t_{1}$ (i.e., $\frac{t_{2}}{t_{1}} \geq \frac{2}{3}$ ), then MCL will cross the left (right) vertical line in market 1 (market 2). However, if $\frac{t_{2}}{t_{1}}<\frac{2}{3}$, then the MCL line will cross both horizontal lines in both markets in period 2.

Remember that in our base model with $\frac{t_{2}}{t_{1}}=1$, we found that BBPD benefits firms at the expense of consumers. After solving the model for $t_{1} \geq t_{2},{ }^{13}$ it can be shown that the sign of the effect of BBPD on profits and consumer welfare prevails as long as $\frac{t_{2}}{t_{1}} \in\left(\gamma_{1}, 1\right]$ with $\gamma_{1} \approx 0.9221$. However, the results become qualitatively different when $\frac{t_{2}}{t_{1}}$ goes down further. In particular, when $\frac{t_{2}}{t_{1}} \in\left(\gamma_{2}, \gamma_{1}\right)$ with $\gamma_{2} \approx 0.8695$, BBPD hurts both firms and consumers. When $\frac{t_{2}}{t_{1}} \in\left(\frac{2}{3}, \gamma_{2}\right)$, BBPD benefits consumers at the expense of firms. When $t_{2}$ is sufficiently small $\left(\frac{t_{2}}{t_{1}}<\frac{2}{3}\right)$, dimension 2 is strongly dominated by dimension $1^{14}$ and our two-dimensional results are qualitatively the same as those obtained in one-dimensional models, thus BBPD is good for consumers but bad for firms. ${ }^{15}$

\footnotetext{
${ }^{12}$ Remember that because consumers buy efficiently under uniform pricing, the permission of BBPD will always have a negative impact on social welfare.

${ }^{13}$ Proofs can be obtained from the authors upon request.

${ }^{14}$ Following Irmen and Thisse (1998) we can say that in our two-period model, dimension 1 is strong dominant when $t_{1}>\frac{3}{2} t_{2}$.

${ }^{15}$ In both cases of $\frac{t_{2}}{t_{1}} \in\left[\frac{2}{3}, 0.8695\right)$ and $\frac{t_{2}}{t_{1}}<\frac{2}{3}$, BBPD benefits consumers at the cost firms. However, profits depend on $t_{2}$ in the former case but not the latter case (due to the irrelevance of the second dimension).
} 


\subsection{Myopic consumers}

So far we have assumed that consumers are forward-looking in the sense that they anticipate that next period prices may depend on their behavior in period 1. Relaxing this assumption in our framework would imply assuming that in period 1 consumers are myopic, which means that they do not anticipate any poaching attempt by firms in the future. The second period equilibrium is obviously the same as in the base model. However, in period 1, each consumer makes his/her purchasing decision solely based on the first-period utility of buying from either firm. The marginal indifferent consumer is characterized by

$$
V-p_{1 A}-t x^{2}-t y^{2}=V-p_{1 B}-t(1-x)^{2}-t(1-y)^{2} .
$$

With myopic consumers, we can directly solve for the marginal consumer located at $\left(x_{1}, 0\right)$, which yields

$$
x_{1}=1-\frac{p_{1 A}-p_{1 B}}{2 t} .
$$

Solving both firms' first period FOCs, it is straightforward to obtain the equilibrium prices and profits. ${ }^{16}$ In the two-dimensional model with myopic consumers, we find that the practice of BBPD softens price competition in the first-period, and so first-period prices are above their non-discrimination counterparts. This is in contrast to the result obtained under a one-dimensional model (Fudenberg and Tirole, 2000) where BBPD has no impact on first period price when consumers are naive. The extension of the base model to myopic consumers shows that forward looking firms do in fact distort their first period price behavior even when consumers are myopic. Therefore, it shows that the practice of BBPD in a two-dimensional setting leads firms to raise first-period prices above the uniform level whether consumers are forward looking or not.

As explained, in general when firms can engage in price discrimination based on purchase history there are two effects on first-period prices: a consumer-side effect and a firm-side effect. When consumers are forward-looking they correctly anticipate lower second period prices, become less price sensitive in period 1 and so there is a positive effect on first-period prices. When firms are forward looking, they also take into account that changes in the first-period price change the first-period cutoff and thus changes the nature of the second-period competition. However, in the one dimensional model of BBPD a change in the first-period price has no effect on second-period profit because with a uniform distribution a firm's marginal gains in one second-period market are exactly offset by losses in the other $\left(\frac{\partial \pi_{2}}{\partial p_{1}}=0\right)$. Thus, in this case the decrease in the price sensitivity of consumers in period 1 that occurs when we move from no discrimination to BBPD fully determines the result of first-period prices above the non-discrimination level.

In the two-dimensional model with a uniform distribution we find that a change in the firstperiod price does not cancel out in the neighborhood of $x_{1}=1$, specifically we find that $\frac{\partial \pi_{2 A}}{\partial p_{1 A}}>0$,

\footnotetext{
${ }^{16}$ Proofs can be obtained from the authors upon request.
} 
suggesting that firm A's marginal gains in one second-period market (higher price $p_{2 A 2}$ targeted to market 2 ) are higher than losses in the other (lower price $p_{2 A 1}$ targeted market 1 ). Thus, firms price above the uniform first-period prices even when consumers are myopic. However as expected firms set higher first-period prices under BBPD with forward-looking consumers.

Regarding the firms' profits with myopic consumers, we find that period 2 profits are higher than their counterparts in a one-dimensional model but below the non-discrimination profit:

$$
\pi_{u}^{2-\text { dimension }}>\pi_{2 i}^{2-\text { dimension }}>\pi_{2 i}^{1-\text { dimension }}, \quad i=A, B .
$$

Further, the first-period profit with BBPD satisfies:

$$
\pi_{1 i}^{2-\text { dimension }}>\pi_{1 i}^{1-\text { dimension }}=\pi_{1 u}^{2-\text { dimension }}, \quad i=A, B .
$$

It is important to stress that in contrast to what happens under forward looking consumers, the assumption of consumers' naivety is bad for overall profits. Indeed, we find that under myopic consumers, although BBPD raises first-period profits, the overall impact on profits is negative. The reason is that the increase in profits in period 1 (due to higher first-period prices even when consumers are naive) is not enough to overcome the decrease in profits in period 2 (due to price discrimination). The economic intuition is the following. The consideration of second period utility in first period purchasing decisions makes consumers less sensitive to price cuts in period 1, allowing firms to further raise prices. This softens price competition in period 1 and raises prices and profits to a level that overcomes the profit loss in period 2. Consequently, when consumers are naive the increase in profits in period 1 is not sufficiently high to overcome the decrease in profits in period 2, suggesting that BBPD is bad for overall industry profits in a two-dimensional model with myopic consumers.

In sum, it is important to stress that the assumption of forward looking versus naive consumers plays a role on the profit effects of BBPD in a two-dimensional symmetric model. When consumers are forward looking the model highlights that BBPD boosts industry profits at the expense of consumer welfare; the reverse happens when consumers are naive.

\section{Conclusion}

The economics literature on oligopoly price discrimination by purchase history has focused uniquely on markets with one-dimensional consumer preferences. When these preferences are fixed across time, dynamic price discrimination by competing firms often results in intensified competition; and such pricing practices typically reduce profits and do not raise consumer welfare concerns.

This article has taken a first step in developing a theory of BBPD in a two-dimensional consumer preferences model. In this new framework, the paper addresses the following questions. How does 
price discrimination by purchase history affect competition and consumers? Should public policies facilitate or prevent the practice of such price discrimination?

In so doing the paper provides useful implications for managers, employing price discrimination strategies; and for policy competition agencies, evaluating the effects of price discrimination based on consumers' purchase history. A standard dilemma for managers engaging in price discrimination based on purchase history, in competitive markets where consumer-preferences are one-dimensional and fixed across time, is that profits fall at the expense of consumer welfare gains. Our analysis reveals that managers might not necessarily face this dilemma when consumer preferences are bi-dimensional. Indeed, the paper highlights that behavior-based price discrimination can be a profitable pricing strategy in markets where consumers are sophisticated and their preferences reasonably well represented by a two symmetric dimensional distribution. For competition policy agencies the paper highlights that conclusions regarding the profit and consumer welfare effects of price discrimination based purchase history do depend on the way consumer preferences are modelled and on what is learned about consumer demand. While BBPD can potentially not raise consumer welfare concerns in one-dimensional models with fixed preferences across time, the reverse might happen when consumer preferences are rather two-dimensional.

In light of the above, this paper has tried to contribute to the ongoing debate on the economic implications of price discrimination based on consumers' past behavior, only made possible in the context of digital markets. The main results of the paper and those in the received literature suggest that the specificity of each market plays an important role in the conclusions derived. Notwithstanding the model addressed in this paper is far from covering all complex aspects of real markets (some of which perhaps not yet known), it provides a theoretical rationale for the increasingly use of new forms of price discrimination strategies only possible in the context of digital markets. As the theoretical model provides empirically testable hypotheses, we hope it can be used for further empirical research.

\section{Appendix: Proofs of Lemmas and Propositions}

\section{Proof of Lemma 2}

In period 1 MCL crosses the bottom horizontal line at $\left(x_{1}, 0\right)$. This gives the following first period demand:

$$
q_{1 A}=\frac{1}{2} x_{1}^{2}, \quad q_{1 B}=1-q_{1 A} .
$$

Next, we consider period 2. MCL crosses bottom horizontal line at $\left(x_{2}, 0\right)$ in market 1 and crosses top horizontal line at $\left(x_{3}, 1\right)$ in market 2 . Using the marginal consumer expression, we can 
obtain

$$
x_{2}=1+\frac{p_{2 B 1}-p_{2 A 1}}{2 t}, \quad x_{3}=\frac{p_{2 B 2}-p_{2 A 2}}{2 t} .
$$

Firms' demand functions are

$$
\begin{gathered}
q_{2 A 1}=\frac{1}{2} x_{2}^{2}, \quad q_{2 B 1}=q_{1 A}-q_{2 A 1}, \\
q_{2 B 2}=\frac{1}{2}\left(1-x_{3}\right)^{2}, \quad q_{2 A 2}=q_{1 B}-q_{2 B 2} .
\end{gathered}
$$

Firm $i=A, B$ 's problem in market $j=1,2$ is,

$$
\max _{p_{2 i j}} \quad \pi_{2 i j}=p_{2 i j} \cdot q_{2 i j}
$$

Solving the FOCs, we can obtain

$$
\begin{aligned}
& p_{2 A 1}=\frac{t}{4}\left(\sqrt{4 x_{1}^{2}+1}+1\right), \quad p_{2 B 1}=\frac{t}{4}\left(3 \sqrt{4 x_{1}^{2}+1}-5\right), \\
& p_{2 A 2}=\frac{t}{4}\left(3 \sqrt{9-4 x_{1}^{2}}-5\right), \quad p_{2 B 2}=\frac{t}{4}\left(\sqrt{9-4 x_{1}^{2}}+1\right) .
\end{aligned}
$$

We need to impose that $p_{2 B 1}=\frac{t}{4}\left(3 \sqrt{4 x_{1}^{2}+1}-5\right) \geq 0$ and $p_{2 A 2}=\frac{t}{4}\left(3 \sqrt{9-4 x_{1}^{2}}-5\right) \geq 0$. From $p_{2 B 1} \geq 0$ we obtain that $x_{1} \geq \frac{2}{3}$. The condition $p_{2 A 2} \geq 0$ is satisfied as long as $0<x_{1}<\frac{1}{3} \sqrt{14}$, which is always true. All the other prices are positive. Therefore, when $\frac{2}{3} \leq x_{1} \leq 1$ :

$$
\begin{aligned}
& p_{2 A 1}=\frac{t}{4}\left(\sqrt{4 x_{1}^{2}+1}+1\right), \quad p_{2 B 1}=\frac{t}{4}\left(3 \sqrt{4 x_{1}^{2}+1}-5\right), \\
& p_{2 A 2}=\frac{t}{4}\left(3 \sqrt{9-4 x_{1}^{2}}-5\right), \quad p_{2 B 2}=\frac{t}{4}\left(\sqrt{9-4 x_{1}^{2}}+1\right) .
\end{aligned}
$$

This proves (ii). To prove (i) note that if $x_{1}<\frac{2}{3}$, then for firm B quoting $p_{2 B 1}<0$ is always strictly dominated by $p_{2 B 1}=0$. Thus, when $x_{1} \leq \frac{2}{3}$ then $p_{2 B 1}=0$. In this case the best firm A can do is to charge $p_{2 A 1}$ satisfying $V-p_{2 A 1}-t x_{1}^{2}=V-0-t\left(1-x_{1}\right)^{2}-t(1-0)^{2}$. This yields $p_{2 A 1}=2 t\left(1-x_{1}\right)$.

When $\frac{2}{3} \leq x_{1} \leq 1$, substituting the prices into the firms' profit functions and then aggregating the profits over the two markets, we can obtain period 2 profits as,

$$
\begin{aligned}
& \pi_{2 A}=\frac{t}{32}\left[-40+\sqrt{1+4 x_{1}^{2}}+24 x_{1}^{2}+\sqrt{1+4 x_{1}^{2}} x_{1}^{2}+19 \sqrt{9-4 x_{1}^{2}}-9 x_{1}^{2} \sqrt{9-4 x_{1}^{2}}\right] \\
& \pi_{2 B}=\frac{t}{32}\left[-24 x_{1}^{2}+9 \sqrt{1+4 x_{1}^{2}} x_{1}^{2}+8+\sqrt{1+4 x_{1}^{2}}+3 \sqrt{9-4 x_{1}^{2}}-x_{1}^{2} \sqrt{9-4 x_{1}^{2}}\right] .
\end{aligned}
$$

When $x_{1}<\frac{2}{3}$, substituting the prices into the firms' profit functions, we obtain period 2 profits as 


$$
\begin{gathered}
\pi_{2 A}=\frac{t}{32}\left[53 x_{1}^{2}-32 x_{1}^{3}-41+19 \sqrt{9-4 x_{1}^{2}}-9 x_{1}^{2} \sqrt{9-4 x_{1}^{2}}\right] \\
\pi_{2 B}=\frac{t}{128}\left(1+\sqrt{9-4 x_{1}^{2}}\right)^{3} .
\end{gathered}
$$

\section{Proof of Lemma 3}

Consider a marginal consumer in period 1. If she purchases from $A$, she will be poached by firm $B$ in period 2, and enjoy an overall utility of

$$
u_{A}=u_{1 A}+\delta \cdot u_{2 B}=\left[V-p_{1 A}-t x^{2}-t y^{2}\right]+\delta\left[V-p_{2 B 1}-t(1-x)^{2}-t(1-y)^{2}\right] .
$$

In contrast, if she purchases from firm $B$ in period 1 , she will be poached by firm $A$ in period 2 and enjoy an overall utility of

$$
u_{B}=u_{1 B}+\delta \cdot u_{2 A}=\left[V-p_{1 B}-t(1-x)^{2}-t(1-y)^{2}\right]+\delta\left[V-p_{2 A 2}-t x^{2}-t y^{2}\right] .
$$

MCL is characterized by $u_{A}=u_{B}$. We consider the specific marginal consumer $\left(x_{1}, 0\right)$ where MCL crosses the bottom horizontal line. Substituting $(x, y)=\left(x_{1}, 0\right)$, we can obtain

$$
u_{A}=u_{B} \Rightarrow\left(p_{1 B}-p_{1 A}\right)+2 t\left(1-x_{1}\right)(1-\delta)+\frac{3 \delta t}{4}\left(\sqrt{9-4 x_{1}^{2}}-\sqrt{4 x_{1}^{2}+1}\right)=0 .
$$

Closed form solution for $x_{1}$ cannot be obtained. Instead, we use implicit function theorem, we can obtain

$$
\frac{d x_{1}}{d p_{1 A}}=-\frac{d x_{1}}{d p_{1 B}}=-\left[2 t(1-\delta)+3 \delta t x_{1}\left(\frac{1}{\sqrt{4 x_{1}^{2}+1}}+\frac{1}{\sqrt{9-4 x_{1}^{2}}}\right)\right]^{-1}
$$

Firm $i=A, B$ 's first period profit is,

$$
\pi_{1 i}=p_{1 i} \cdot q_{1 i}
$$

and their overall discounted profit is

$$
\pi_{i}=\pi_{1 i}+\pi_{2 i}, \quad i=A, B
$$

A change in $p_{1 A}$ affects $\pi_{A}$ through 3 channels: (i) directly through $p_{1 A}$ on $\pi_{1 A}$; (ii) indirectly through $x_{1}$ on $\pi_{1 A}$; (iii) indirectly through $x_{1}$ on $\pi_{2 A}$ (needs discounting). Similarly for firm $B$.

FOCs are given by

$$
\frac{\partial \pi_{A}}{\partial p_{1 A}}=\frac{\partial \pi_{1 A}}{\partial p_{1 A}}+\frac{\partial \pi_{1 A}}{\partial x_{1}} \cdot \frac{d x_{1}}{d p_{1 A}}+\delta \frac{\partial \pi_{2 A}}{\partial x_{1}} \cdot \frac{d x_{1}}{d p_{1 A}}=0
$$




$$
\frac{\partial \pi_{B}}{\partial p_{1 B}}=\frac{\partial \pi_{1 B}}{\partial p_{1 B}}+\frac{\partial \pi_{1 B}}{\partial x_{1}} \cdot \frac{d x_{1}}{d p_{1 B}}+\delta \frac{\partial \pi_{2 B}}{\partial x_{1}} \cdot \frac{d x_{1}}{d p_{1 B}}=0
$$

Next, we solve $\frac{\partial \pi_{B}}{\partial p_{1 B}}=0$ to obtain $p_{1 B}$. The expression is too lengthy to report, but it contains $x_{1}$ which depends on $p_{1 B}$. We also use equation 8 to solve for $p_{1 A}$. After normalizing $t=1, \frac{\partial \pi_{A}}{\partial p_{1 A}}$ is a function of $\delta$ and $x_{1}$ only. We then plot the value of $\frac{\partial \pi_{A}}{\partial p_{1 A}}$ for $\delta \in[0,1]$ and $x_{1} \in[0,1]$. We find that $\frac{\partial \pi_{A}}{\partial p_{1 A}}=0$ if $x_{1}=1$, and $\frac{\partial \pi_{A}}{\partial p_{1 A}}<0$ if $x_{1}<1$.

At $x_{1}=1$, we have $p_{1 A}=p_{1 B}$ so there exists no asymmetric equilibrium.

\section{Proof of Proposition 1}

In Lemma 3, we have shown that there is no asymmetric equilibrium. In particular, both firms FOCs are satisfied only when $x_{1}=1$ in which case we have

$$
p_{1 A}=p_{1 B}=\frac{13 \sqrt{5}-25}{10} \delta t+t
$$

We then substitute them to obtain the second period prices

$$
p_{2 A 1}=p_{2 B 2}=\frac{\sqrt{5}+1}{4} t, \quad p_{2 A 2}=p_{2 B 1}=\frac{3 \sqrt{5}-5}{4} t,
$$

and profits

$$
\pi_{2 A}=\pi_{2 B}=\frac{3 \sqrt{5}-4}{8} t
$$

Firm $i=A, B$ 's overall discounted profit is

$$
\pi_{i}=\pi_{1 i}+\delta \pi_{2 i}=\frac{41 \sqrt{5}-70}{40} \delta t+\frac{t}{2} .
$$

This is the only equilibrium candidate. Next, we verify that no firm has an incentive to deviate unilaterally. For either firm, there are only two deviations: reduces or raises first-period price.

We first rule out firm's incentive to raise first period price. Fix $p_{1 B}$ and assume that firm $A$ increases $p_{1 A}$. This leads to $x_{1}<1$ so our assumed demand structure still holds. In Proof of Lemma 3, we have shown that $\frac{\partial \pi_{A}}{\partial p_{1 A}}<0$ if $x_{1}<1$. Therefore, firm $A$ has no incentive to raise $p_{1 A}$.

Next, we rule out incentives to reduce first period price. Fix $p_{1 A}$ and assume that firm $B$ lowers $p_{1 B}$. This leads to $x_{1}<1$ so our assumed demand structure still holds. Following similar analysis as above, we find that $\frac{\partial \pi_{B}}{\partial p_{1 B}}>0$ if $x_{1}<1$. Therefore, firm $B$ has no incentive to lower $p_{1 B}$.

Combined, neither firm has an incentive to raise or lower first period prices. Therefore, the first period prices we calculated, together with the corresponding second period prices, form the unique subgame perfect Nash equilibrium. Using the price expressions, we can also obtain the equilibrium profits in period 2 and overall profits. 


\section{References}

Chen, Y. (1997), Paying Customers to Switch, Journal of Economics and Management Strategy, $6,877-897$.

Chen, Y. (2005), Oligopoly Price Discrimination by Purchase History, The Pros and Cons of Price Discrimination, The Swedish Competition Authority, Stockholm, 101-130.

Chen, Y. and Pearcy, J. (2010), Dynamic Pricing: when to Entice Brand Switching and when to Reward Consumer Loyalty, RAND Journal of Economics, 41, 674-685.

Corts, K. (1998), "Third-degree price discrimination in oligopoly: all-out competition and strategic commitment", RAND Journal of Economics, 29, 306-323.

Esteves, R.B. (2009), A Survey on the Economics of Behaviour-Based Price Discrimination, NIPE Working Paper 5/2009.

Esteves, R.B. (2010), Pricing with Customer Recognition, International Journal of Industrial Organization, 28, 669-681.

Esteves, R. B. and Reggiani, C. (2014). Elasticity of demand and behaviour-based price discrimination. International Journal of Industrial Organization, 32, 46-56.

Fudenberg, D. and Tirole, J. (2000), Customer Poaching and Brand Switching, RAND Journal of Economics, 31, 634-657.

Fudenberg, D. and Villas-Boas, M. (2006), Behavior-Based Price Discrimination and Customer Recognition, In T. Hendershott (ed.), Handbook on Economics and Information Systems, NorthHolland, Amsterdam.

Irmen, A., and Thisse, J. (1998). Competition in multi-characteristics spaces: Hotelling was almost right. Journal of Economic Theory, 78, 76-102.

Liu, Q., and Shuai, J. (2013). Multi-dimensional price discrimination. International Journal of Industrial Organization, 31, 417-428.

Lyons, B.R. (2002). Could politicians be more right than economists? A theory of merger standards. Centre for Competition and Regulation, UEA Norwich.

Shin, J., and Sudhir, K. (2010). A customer management dilemma: When is it profitable to reward one's own customers?. Marketing Science, 29, 671-689. 
Stole, L. (2007), Price Discrimination in Competitive Environments, In Armstrong, M. and R. Porter (eds.), The Handbook of Industrial Organization 3, Amsterdam: North-Holland.

Tabuchi, T. (1994). Two-stage two-dimensional spatial competition between two firms. Regional Science and Urban Economics, 24, 207-227.

Taylor, C. (2003), Supplier Surfing: Competition and Consumer Behaviour in Subscription Markets, RAND Journal of Economics, 34, 223-246.

Villas-Boas, M. (1999), Dynamic Competition with Customer Recognition, RAND Journal of Economics, 30, 604-631. 


\section{Most Recent Working Paper}

\begin{tabular}{|c|c|}
\hline $\begin{array}{l}\text { NIPE WP } \\
04 / 2016\end{array}$ & $\begin{array}{l}\text { Esteves, Rosa-Branca, Qihong Liu e Jie Shuai, "Behavior-Based Price Discrimination in a } \\
\text { Multi-Dimensional Preferences Market" }\end{array}$ \\
\hline $\begin{array}{c}\text { NIPE WP } \\
03 / 2016\end{array}$ & $\begin{array}{l}\text { Bleaney, Michael e Manuela Francisco, "Real Exchange Rate Volatility: Is Sub-Saharan Africa } \\
\text { Different?" }\end{array}$ \\
\hline $\begin{array}{c}\text { NIPE WP } \\
02 / 2016\end{array}$ & $\begin{array}{l}\text { Castro, Vítor e Rodrigo Martins, "Politically driven cycles in fiscal policy: In depth analysis of } \\
\text { the functional components of government expenditures", } 2016\end{array}$ \\
\hline $\begin{array}{c}\text { NIPE WP } \\
01 / 2016\end{array}$ & $\begin{array}{l}\text { Bouchellal, Abdellah e Vítor Castro, "On the length of bank-firm relationships: An empirical } \\
\text { application to a major French bank", } 2016\end{array}$ \\
\hline $\begin{array}{l}\text { NIPE WP } \\
17 / 2015\end{array}$ & $\begin{array}{l}\text { Loureiro, Gilberto e Sónia Silva, "Post-Operating Performance Of Cross-Delisted Firms From } \\
\text { U.S. Stock Exchanges", } 2015\end{array}$ \\
\hline $\begin{array}{l}\text { NIPE WP } \\
16 / 2015\end{array}$ & $\begin{array}{l}\text { Loureiro, Gilberto e Sónia Silva, "Earnings Management and Stock Price Crashes Post } \\
\text { Crossdelisting", } 2015\end{array}$ \\
\hline $\begin{array}{c}\text { NIPE WP } \\
15 / 2015\end{array}$ & $\begin{array}{l}\text { Gilberto Loureiro e Sónia Silva, "Cross-Delisting, Financial Contraints and Investment } \\
\text { Sensitivities", } 2015\end{array}$ \\
\hline $\begin{array}{c}\text { NIPE WP } \\
14 / 2015\end{array}$ & $\begin{array}{l}\text { Fauver, Larry, Gilberto Loureiro e Alvaro G. Taboada, "Equity Offerings, Stock Price Crash } \\
\text { Risk, and the Impact of Securities Regulation: International Evidence", } 2015\end{array}$ \\
\hline $\begin{array}{c}\text { NIPE WP } \\
13 / 2015\end{array}$ & $\begin{array}{l}\text { Pereira, Paulo J. e Artur Rodrigues, “A theory on merger timing and announcement returns", } \\
2015\end{array}$ \\
\hline $\begin{array}{l}\text { NIPE WP } \\
12 / 2015 \\
\end{array}$ & $\begin{array}{l}\text { Bernardino, Susana e Santos, J. Freitas, "Financing social ventures by crowdfunding: The } \\
\text { influence of entrepreneurs' personality traits", } 2015\end{array}$ \\
\hline $\begin{array}{l}\text { NIPE WP } \\
11 / 2015\end{array}$ & $\begin{array}{l}\text { D’Almeida, André Corrêa e Paulo Reis Mourão, “The Irrelevance of Political Parties’ } \\
\text { Differences for Public Finances - Evidence from Public Deficit and Debt in Portugal (1974 } \\
\text { 2012)”, } 2015\end{array}$ \\
\hline $\begin{array}{c}\text { NIPE WP } \\
10 / 2015\end{array}$ & $\begin{array}{l}\text { Santos, José Freitas, Laurentina Vareiro, Paula Remoaldo e J. Cadima Ribeiro, "Mega cultural } \\
\text { events: Does attendance affect residents' perceptions of a city’s identity?", 2015 }\end{array}$ \\
\hline $\begin{array}{c}\text { NIPE WP } \\
09 / 2015 \\
\end{array}$ & $\begin{array}{l}\text { Brekke, Kurt R., Rosella Levaggi, Luigi Siciliani e Odd Rune Straume, "Patient Mobility and } \\
\text { Health Care Quality when Regions and Patients Differ in Income", } 2015\end{array}$ \\
\hline $\begin{array}{l}\text { NIPE WP } \\
08 / 2015\end{array}$ & $\begin{array}{l}\text { Cellini , Roberto, Luigi Siciliani e Odd Rune Straume, “A dynamic model of quality } \\
\text { competition with endogenous prices", } 2015\end{array}$ \\
\hline $\begin{array}{c}\text { NIPE WP } \\
07 / 2015\end{array}$ & $\begin{array}{l}\text { Brekke, Kurt R., Tor Helge Holmås, Karin Monstad e Odd Rune Straume, “Do Treatment } \\
\text { Decisions Depend on Physicians' Financial Incentives?", } 2015\end{array}$ \\
\hline $\begin{array}{c}\text { NIPE WP } \\
06 / 2015\end{array}$ & $\begin{array}{l}\text { Brekke, Kurt R., Chiara Canta e Odd Rune Straume, "Does Reference Pricing Drive Out } \\
\text { Generic Competition in Pharmaceutical Markets? Evidence from a Policy Reform", } 2015\end{array}$ \\
\hline $\begin{array}{l}\text { NIPE WP } \\
05 / 2015 \\
\end{array}$ & $\begin{array}{l}\text { Brekke, Kurt R., Tor Helge Holmäs, Karin Monstad e Odd Rune Straume, "Socioeconomic } \\
\text { Status and Physicians`Treatment Decisions", } 2015\end{array}$ \\
\hline $\begin{array}{l}\text { NIPE WP } \\
04 / 2015\end{array}$ & $\begin{array}{l}\text { Castro, Vítor e Rodrigo Martins, "Budget, expenditures composition and political manipulation: } \\
\text { Evidence from Portugal”, } 2015\end{array}$ \\
\hline $\begin{array}{c}\text { NIPE WP } \\
03 / 2015 \\
\end{array}$ & Maria Thompson, “Social Capital, Innovation and Economic Growth”, 2015 \\
\hline $\begin{array}{l}\text { NIPE WP } \\
02 / 2015 \\
\end{array}$ & $\begin{array}{l}\text { Kurt R. Brekke, Chiara Canta, Odd Rune Straume, "Reference pricing with endogenous generic } \\
\text { entry", } 2015\end{array}$ \\
\hline $\begin{array}{c}\text { NIPE WP } \\
01 / 2015\end{array}$ & $\begin{array}{l}\text { Aguiar-Conraria, Luís, Pedro Brinca, Haukur Viðar Guðjónsson e Maria Joana Soares } \\
\text { "Optimum Currency Area and Business Cycle Synchronization Across U.S. States", } 2015\end{array}$ \\
\hline $\begin{array}{l}\text { NIPE WP } \\
23 / 2014 \\
\end{array}$ & $\begin{array}{l}\text { Morozumi, Atsuyoshi, Francisco José Veiga e Linda Gonçalves Veiga, "Electoral effects on } \\
\text { the composition of public spending and revenue: evidence from a large panel of countries", } 2014\end{array}$ \\
\hline $\begin{array}{l}\text { NIPE WP } \\
22 / 2014\end{array}$ & $\begin{array}{l}\text { Castro, Vítor e Rodrigo Martins, "Are there political cycles hidden inside government } \\
\text { expenditures?", } 2014\end{array}$ \\
\hline $\begin{array}{l}\text { NIPE WP } \\
21 / 2014 \\
\end{array}$ & $\begin{array}{l}\text { Conceição, Oscarina e Ana Paula Faria, "Determinants of research-based spin-offs survival”, } \\
2014\end{array}$ \\
\hline $\begin{array}{l}\text { NIPE WP } \\
20 / 2014\end{array}$ & a e Margarida \\
\hline
\end{tabular}

